\title{
MODERN LOGISTICS: CASE STUDY ON JSW CRM2 TOTAL AUTOMATIC YMS AND ASRS*
}

\author{
Gajraj Rathore \\ Jagannathan Rajagopalan ${ }^{2}$ \\ Mikko Rissanen ${ }^{3}$
}

\begin{abstract}
With the advent of modern HRM ( Hot rolling mills) with capacities beyond 5 Million tons with corresponding enriched CRM (Cold Rolling Mill) capacities, the throughput per hour exceeds invariably beyond 50 coils per hour making it possible to manage, track, handle, transport, store and dispatch inevitably with an automation system supplemented by corresponding software and hardware. This is true with respect to the production of Cold rolled Annealed, Galvanized, Continuously Annealed, Galvalume, CRGO, CRNGO and Colour coated coils which need total care in handling, tracking and dispatch. Understanding the above needs precisely JSW, Vijayanagar, India, has rightly gone in for a total automatic Yard management system and ASRS wherein the coils are handled as much as possible automatically in cradles without any damage insuring the receipt of coils to the customer as was produced. This CRM 2 has been commissioned and is operating with maximum automation with least manpower and max productivity with assured quality and safety. Pesmel OY Finland had the opportunity to Design, Supply and Commission this system which is first in the country and this technical paper analyses the above project as a case study enlisting the sound technical aspects as well as emphasis on the techno economics with assured ROI (Return on investment) and enhanced efficiency.
\end{abstract}

Keywords: JSW; Jindal steel works; YMS: Yard management system; WMS: Ware house management system; ASRS: Automatic storage and retrieval system.

BSc Engineering , Executive Vice President, JSW Steel Ltd. India.

MSc Engineering, Managing Director, Pesmel South Asia, India.

BSc Industrial Management and Engineering, Area Sales Manager, Pesmel Oy, Finland. 


\section{INTRODUCTION}

Conducting advanced simulation study in projects has become the state of the art technology, today to assess the constraints in material handling and flow in advance so that the same could be streamlined in real situation basis through simulation to save on unnecessary buildings, cranes and resources.

Similarly automatic Yard Management System (YMS) with yard mapping has become the need of the hour when the number of coils to be handled, tracked and processed per hour increases beyond a value which could be handled manually.

Automatic Storage and Retrieval system (ASRS) insures storing of the coils vertically in a compact space utilizing the volume so as to store 12 to 14 full coils of $>25 \mathrm{~T}$ in a compact space of 7 square meter which is the area required to store single coil if it were to be stored on ground. In addition to be able to store more number of coils in a given area the in feed and retrieval rate namely the throughput per hour could also be as high as 50 per hour with the modern high speed vertical stacker cranes utilizing the Ware House Management system. An added feature on this ASRS is the Rack Supported Ware House which does not need the building for the storage as the racks which have the high modulus of rigidity are utilized to support the roof and side cladding thus avoiding a separate building for storage.

The above three modern tools were used in JSW CRM2 to cope up with their production and throughput level with least buildings and resources.

\section{BACKGROUND}

JSW Bellary has been exploring on the possibilities of having automation in their Cold rolling mills for coil transportation and in CRM1 itself right in the year 2007 and they attempted to have certain automation but it was late considering the layout and construction drawings, which were frozen that time.

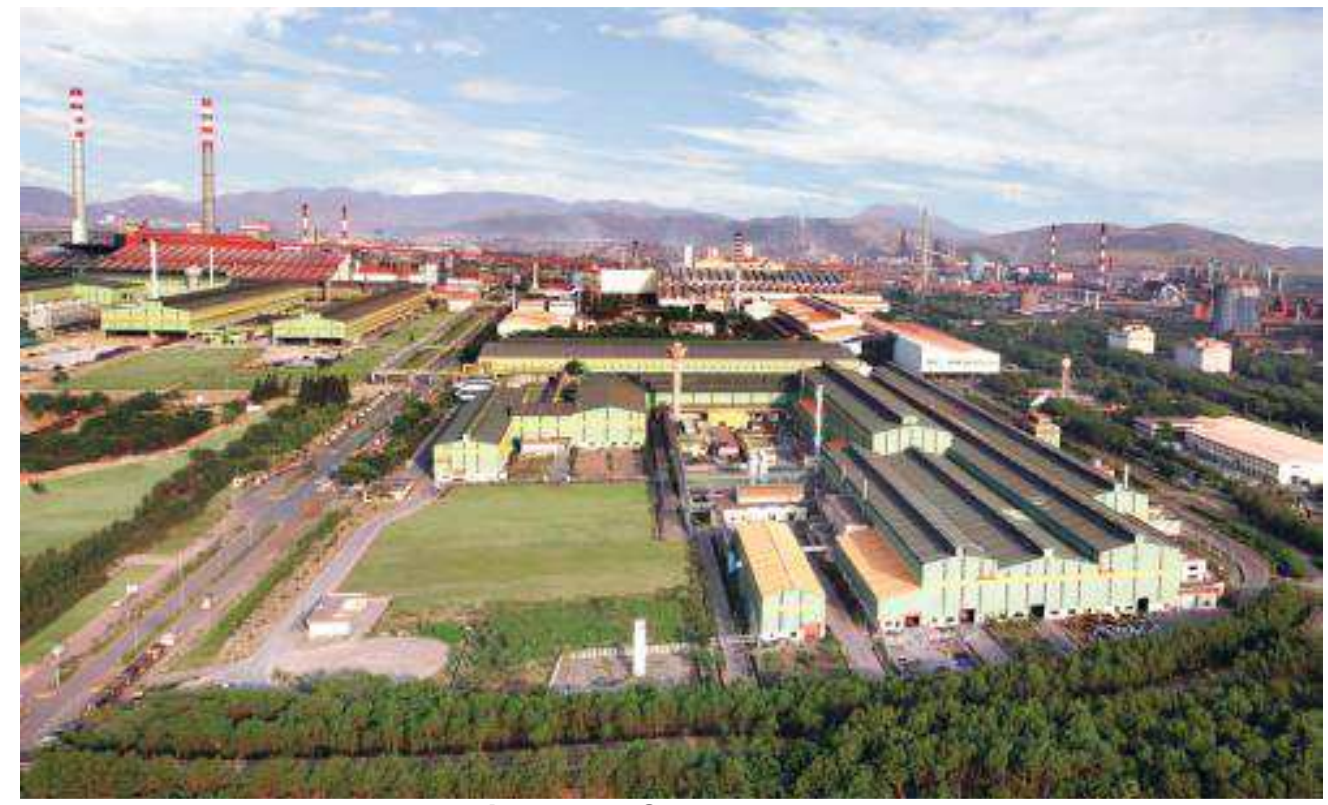

Figure 1: JSW Bellary Mill

Having understood the benefits of automation on material handling they had planned the same for the CRM2 and worked towards the same right at the concept stage with Configuration and Simulation study carried out to find out on the best way of handling 
material handling and internal logistics. Having got convinced technically and operation aspect on the benefits of automation including automatic Yard Management System and ASRS there were many joint exercises on techno economics and return on investment which took many revisions of the lay out till the ideal lay out with best techno economics was achieved.

Upon finding out that with vertical storage they could store 14 coils in the area of storage for one coil on floor which means more than 3 additional buildings of approx. $35000 \mathrm{Sq} \mathrm{M}$ needing additional crane and many operators and other resources could be avoided they chose to go in for the ASRS option in place of floor storage.

Similarly on yard management it was analyzed jointly and found that automatic yard management system using the four way and two way coil cars could save many resources and cranes in addition to insuring higher throughputs insuring no damage to the annealed and coated coils. These technical aspects of the simulation study, Yard Management and ASRS of this project are discussed in this paper in detail.

\section{ADVANCED CONFIGURATION AND SIMULATION STUDY}

Material handling is an essential feature in a steel plant wherein the coils are transported from the Hot rolling mill to cold rolling mill complex and upon receipt and storage the HR coils are sequentially fed to the Pickling and Tandem cold rolling mill Line and upon completion of rolling the coils are received and stored and again distributed to the next operation let it be Galvanizing or Continuous annealing or direct dispatch as CR full hard material. Similarly at the exit of the process lines the material is received and routed towards the Recoiling line or Recoiling and tension leveling line followed by which it is taken in to the automatic packing lines and then to the delivery storage and dispatch.

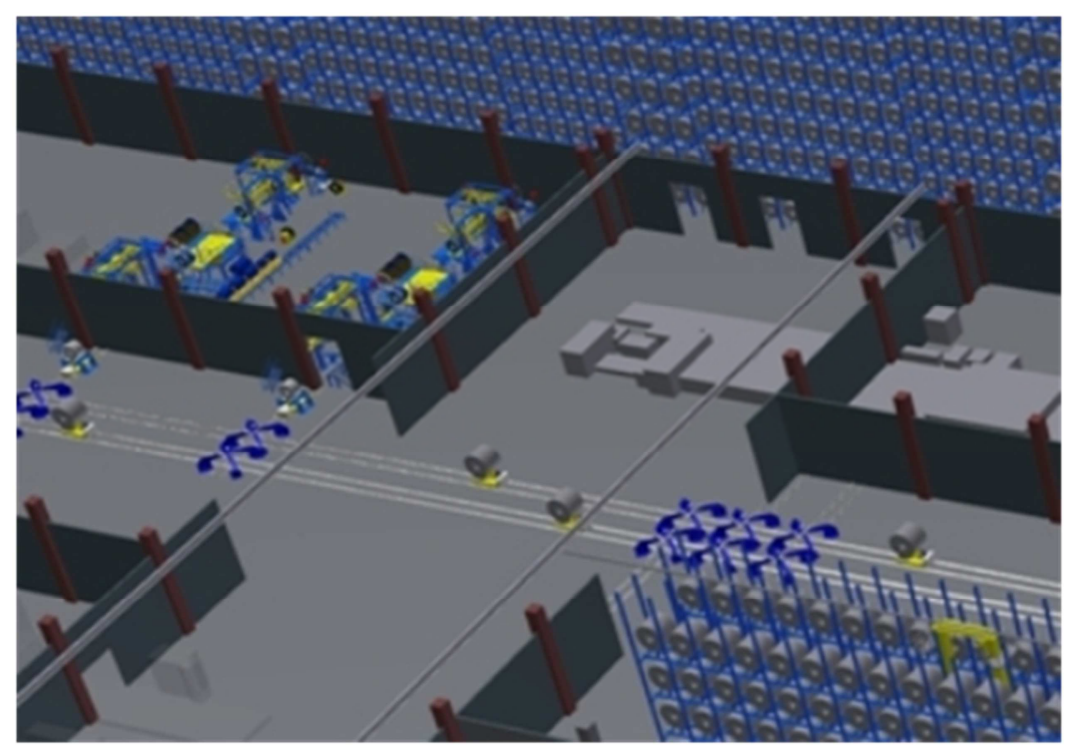

Figure 2: Typical option with WIP (Work in Progress) and FG (Finished Goods) ASRS (Automatic Storage and Retrieval System)

To work out on the automatic cost effective and efficient coil transfer and storage system in line with the transition planning norms need a thorough study of the hardware and program (software) requirement zone wise becomes the configuration of the plant. Thus the configuration study is a preliminary study assuming the through 
put requirement and the SKUs ( stock keeping units) so as to arrive at an optimum solution for sensible material handling without duplicate handling as well as with minimum bottlenecks.

The configuration study also specifies the automation level for a situation wherein the through put is high for example $>10$ coils per hour, in which case manual handling and tracking could become costlier, non productive and unsafe activity and well engineered automation with suitable coil cars and AGVs become a better option. Thus configuration study helps in arriving at the mode of material handling system with specification of each hardware required. Configuration study could help in choosing the type of Mill arrangement with modern concept considering process and material movement and the examples are shown below in Figure 3 and 4.

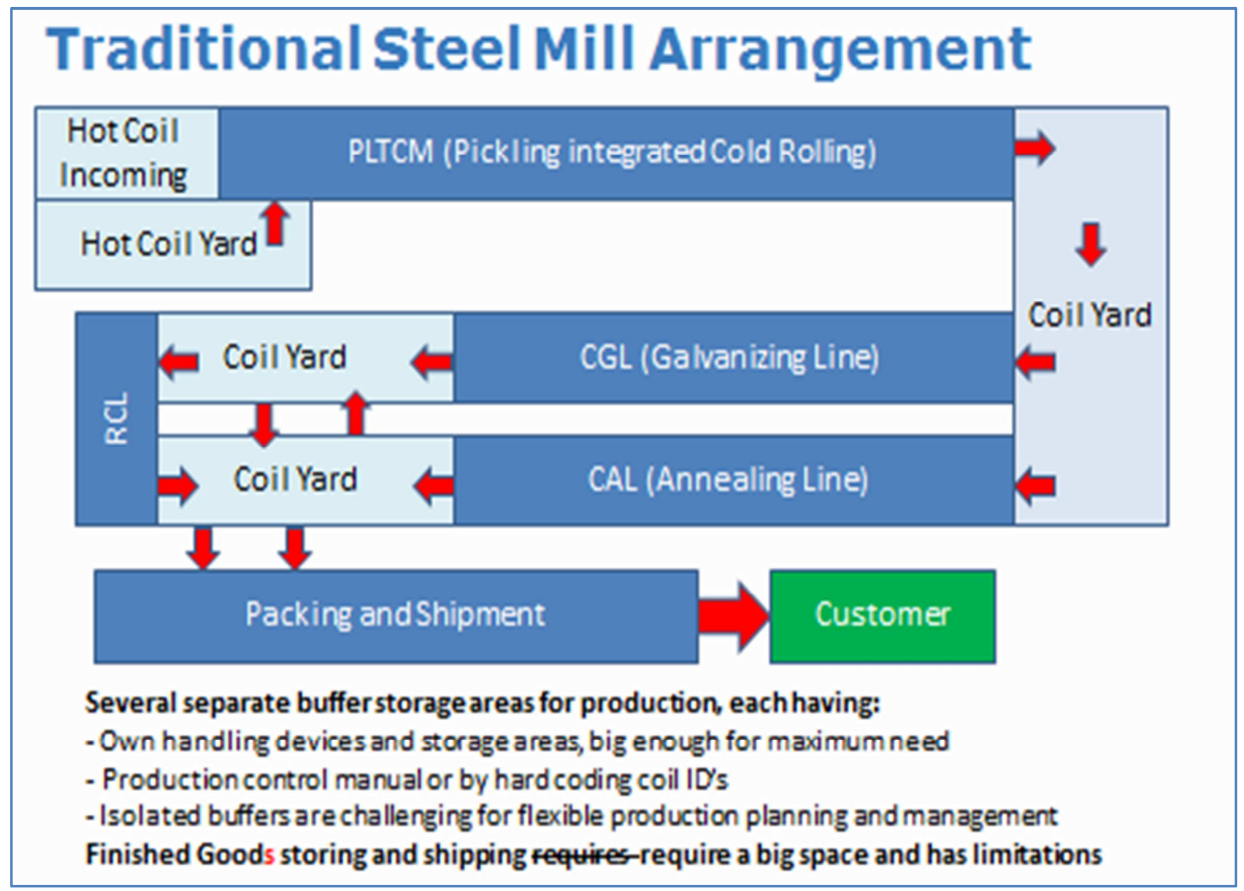

Figure 3: Traditional steel mill arrangement 


\section{Modern Steel Mill Arrangement}

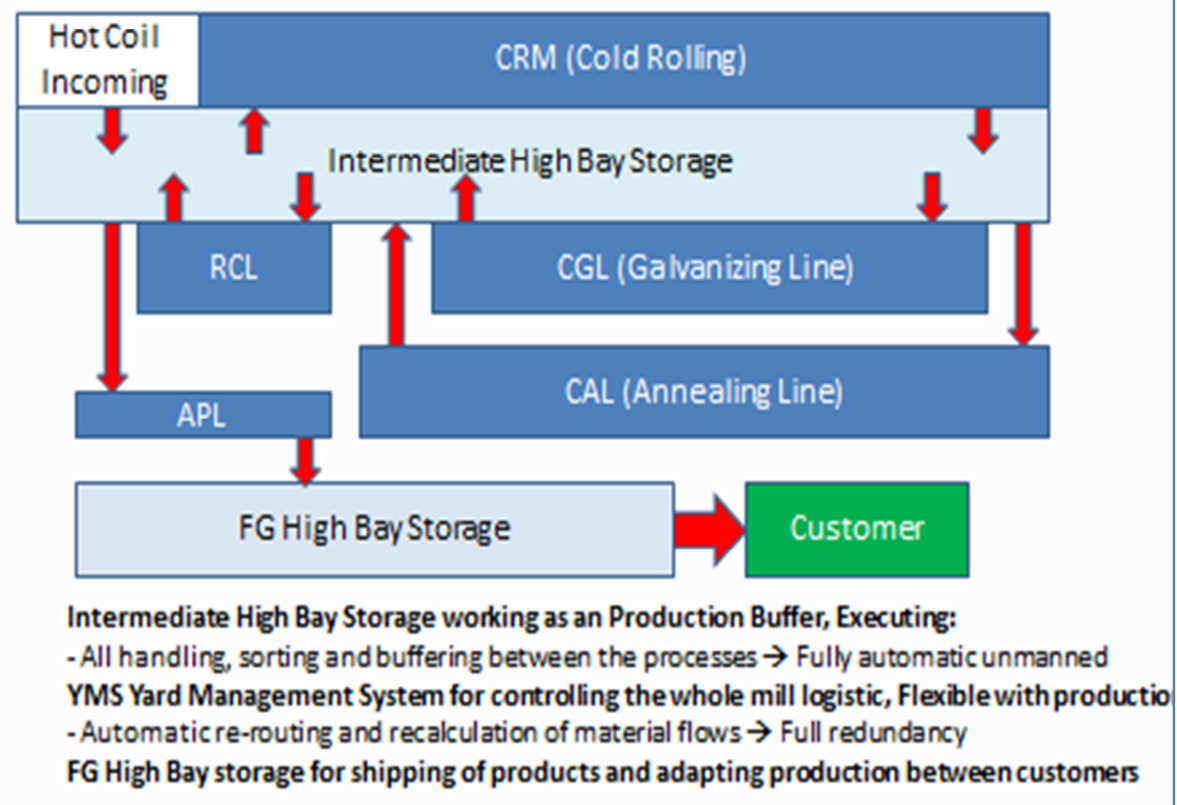

Figure 4: Modern steel mill arrangement

The fundamental differences between the traditional and modern concepts are:

a. The dependency on the EOT cranes are minimum in modern concept with coil cars feeding in and taking out the coils from process and finishing lines.

b. Centralized storage for WIP to distribute the coils with one storage to all finishing equipment

c. A common storage for dispatch for both wagons and trucks

\subsection{Simulation Study}

Once configuration analysis is done and a basic lay out with both hardware like EOT cranes, coil cars and AGV including the storage device like ASRS that may be required are frozen to know the cycle time as well as the quantity of hardware required, simulation study is essential in which the EOT cranes and coil cars as well as the coils themselves are in movement on real time basis through the simulation software in $3 \mathrm{D}$ wherein the parameters could be changed to arrive at the optimum numbers of cranes, coil cars, storage place area or number of places by simulation of the actual situation. This helps in testing the configuration as well as the resources before actually installing the plant which becomes a vital tool for assessing the practical situation and plan for the same especially the critical paths and critical areas. 


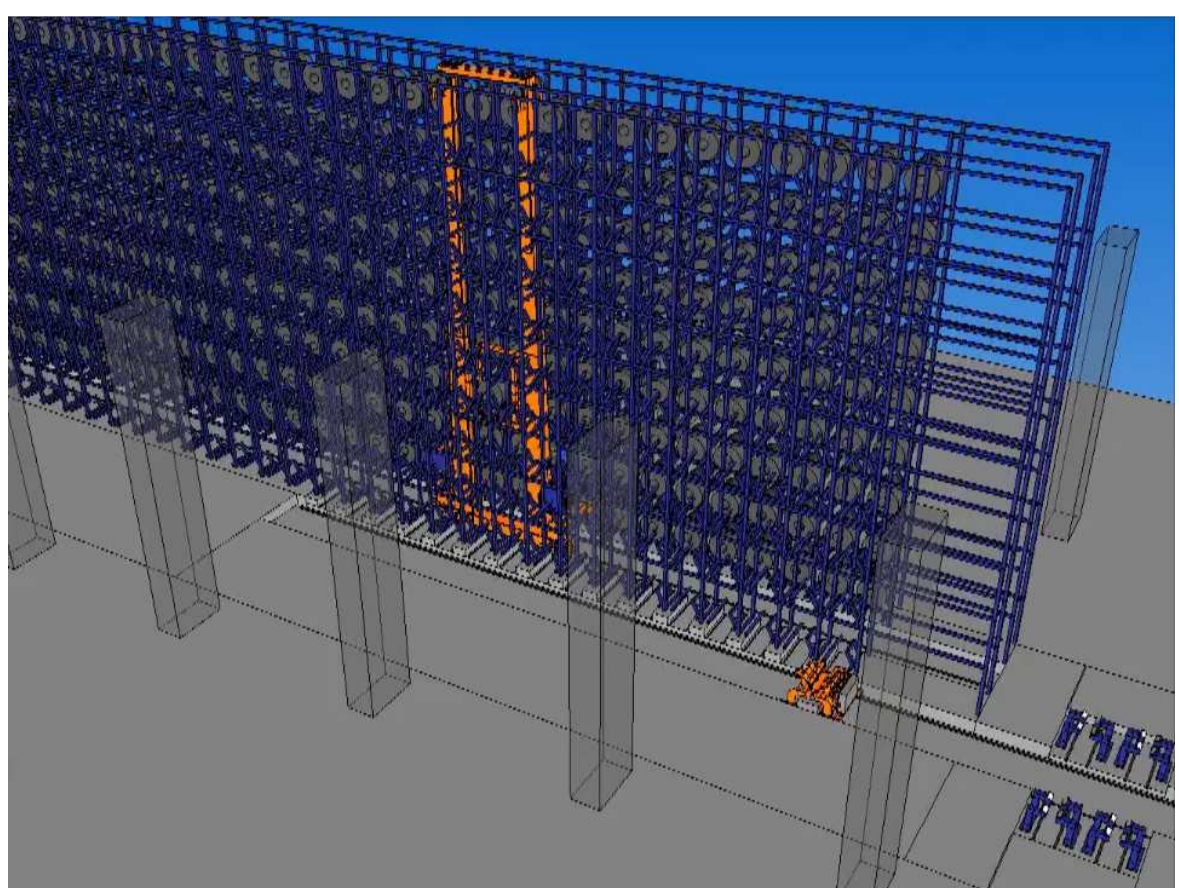

Figure 5: Typical ASRS with stacker crane and out feeding moving coil skids

Simulation study and preparing simulation lay out takes time but once completed it becomes crystal clear for all involved in the project, operation and maintenance on the Line configuration and resources for the corresponding productivity and storage inventories. While there are many options available on the configuration the simulation study helps in pin pointing the optimum or ideal configuration with the resources like number of cranes, coil cars, Man power etc.

This avoids duplicate planning or duplicate investment and becomes an essential tool for the project.

Consensus amongst project, operation and maintenance is easily reached once based on the scientific simulation analysis the resources list is evolved.

\subsection{Typical Steps involved in Configuration and simulation study: Automation and YMS: Configuration study: a convenient staircase?}

Automation in material handling and complete automatic Yard management system is normally a staircase where the plants or warehouse with brownfield project plan to go for upgrading their material handling and feeding and distribution system. Whereas for a greenfield project the appropriate level of automation and yard management system could be chosen right from day one with corresponding skilled and minimum operator and engineering resource.

1) Simulation and configuration study are the cost effective means of checking and configuring the Plant lay out both considering the Process line features and the Material handling features carefully integrating them together towards best efficiency.

2) Configuration study not only covers the lay out but also deals with the individual lines in-feeding and out- feeding systems with appropriate storage areas and system along with the way the product is packed and handled before being shipped to the customer. 
3) Except for the proper process line and finishing line operational features the configuration study addresses the through put right from the mother mill till the finishing storage to dispatch to customer.

4) The findings of the configuration study are cross checked by real time simulation with simulation software packages so as arrive at the best capacity of the Hardware, (material handling equipment like cranes, coil cars, AGvs, transfer cars, transfer conveyors) Building area, type of storages, Cycle time and through put adequacy.

5) Simulation study thus optimizes the Lay out and resources so as to save money by avoiding any duplicate and over design and redundancy which means real saving cost.

6) It is suggested in this paper that in addition to having traditional feasibility study of the project based on the Marketing aspect and Process aspect, it is quite profitable to assess the configuration study and simulation study to insure the smooth Material movement which would be of immense use for insuring the Safety, Enhanced Productivity with quality to achieve the business's ultimate goal namely consistent profitability.

7) "Companies must anticipate customer needs, must be quick to adapt to change, and are responsive to customer wishes." One prime aspect every customer expects from their suppliers is a modern Material handling, tracking and dispatch system and a modern and automatic material handling, packing and storage with retrieval system becomes a vital sales tool for the organization for best CRM (customer relations management insuring customer retention).

8) When you analyze whether or not the return on the investment in technology is automatically higher than your investment in humans, you will find it totally true with respect to Simulation study and Automation with respect to Material Handling and Automatic storage and retrieval system (ASRS).

9) Prescribed Steps : 


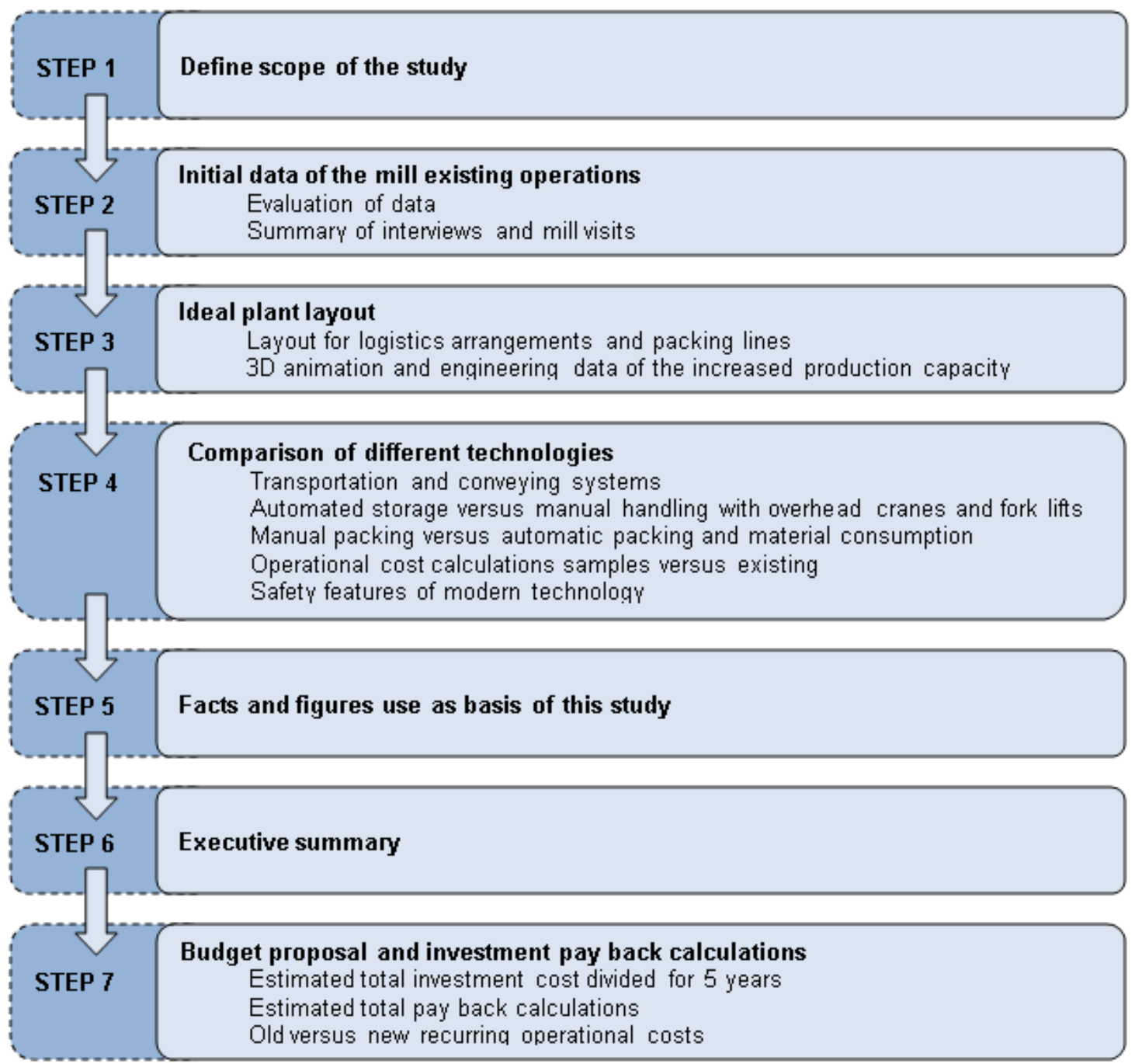

Figure 6: Systematic steps for Configuration and Simulation Study

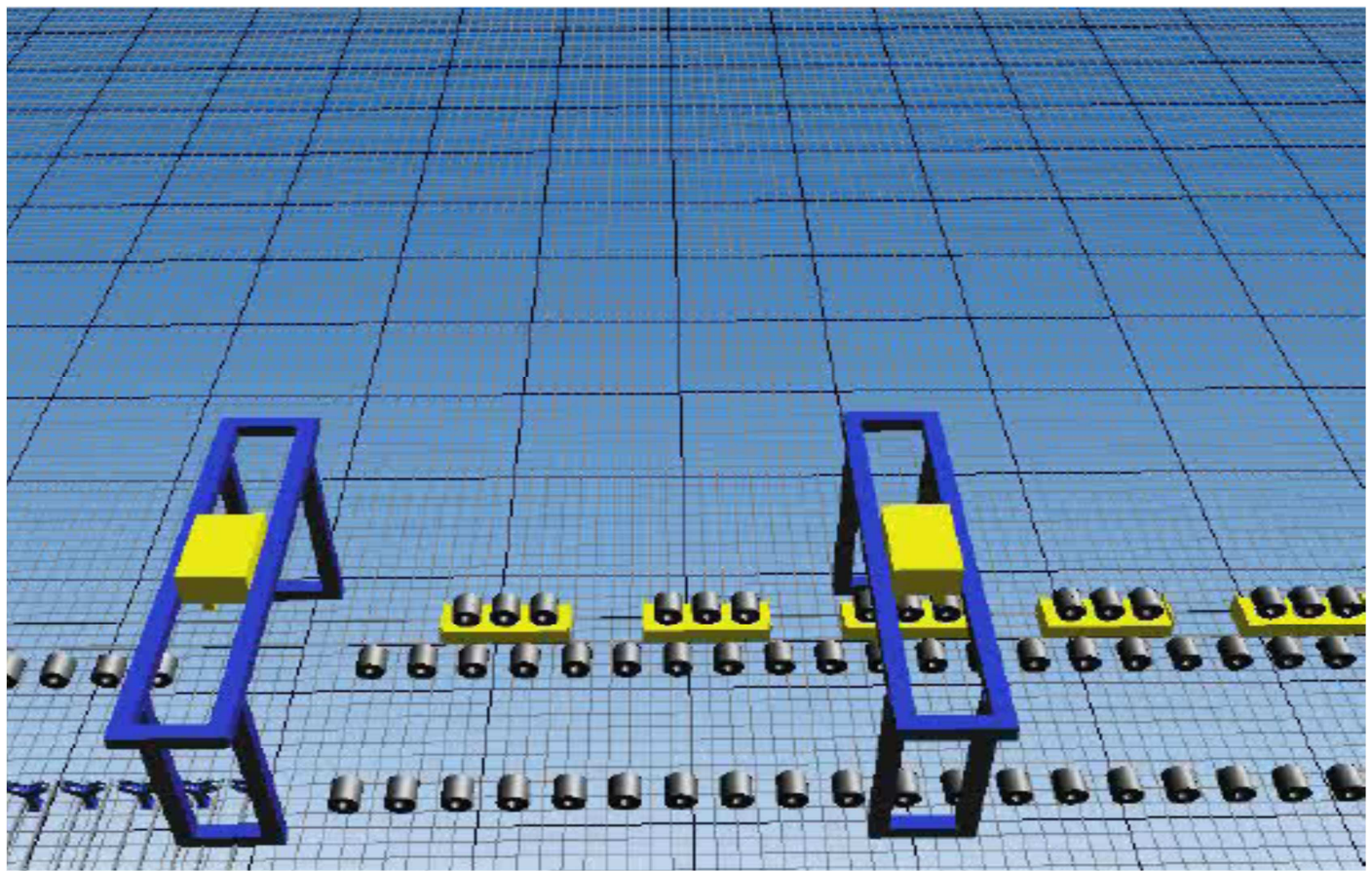

Figure 7: PLTCM entry typical simulation for wagon unloading 


\subsection{Simulation Study at JSW Bellary}

In JSW Bellary Configuration and Simulation study was conducted first and a clear layout based on process flow and material handling avoiding bottle necks was prepared. With analysis all variations on throughputs were checked and the right amount of buildings, EOT cranes and other resources were chosen based on scientific simulation with actual real time production, transportation and dispatch conditions. The two main pillars of modern logistics are identifying that EOT cranes are only meant for lifting and placing and not for distribution due to its inherent slow speed. Adequate numbers of special coil cars supplement the cranes with respect to the distribution of the coils through out the bay.

Simulation was done by dividing the CRM 2 in to four parts namely PLTCM entry, PLTCM exit, WIP and Finished goods storage and dispatch. Figure 4 shows typical simulation concept at PLTCM entry area.

\section{AUTOMATIC YARD MANAGEMENT SYSTEM}

Automatic yard management system has its hardware and software component. The hardwares are normally the EOT Cranes and in modern system the cranes are converted as automatic cranes in addition they are supplemented by two way and four way coil cars as well as by AGVs. (Automatic guided vehicles). Normally $60 \%$ of the jobs on transportation namely the distribution of the coil through out the respective bays are addressed by the special high speed coil cars on floor transportation and $40 \%$ of the transfer jobs like picking and placing on the coil cars or trucks or wagons are addressed by the EOT cranes. This insures corresponding savings on the buildings, cranes and manpower. Normally the modern systems operate totally automatic and only for the purpose of dispatch to the trucks and wagons the crane operators are required considering the un-/non-standardized transport vehicles. Figures 8 to 10 show the concepts on the traditional and modern yard management system with corresponding layout merits.
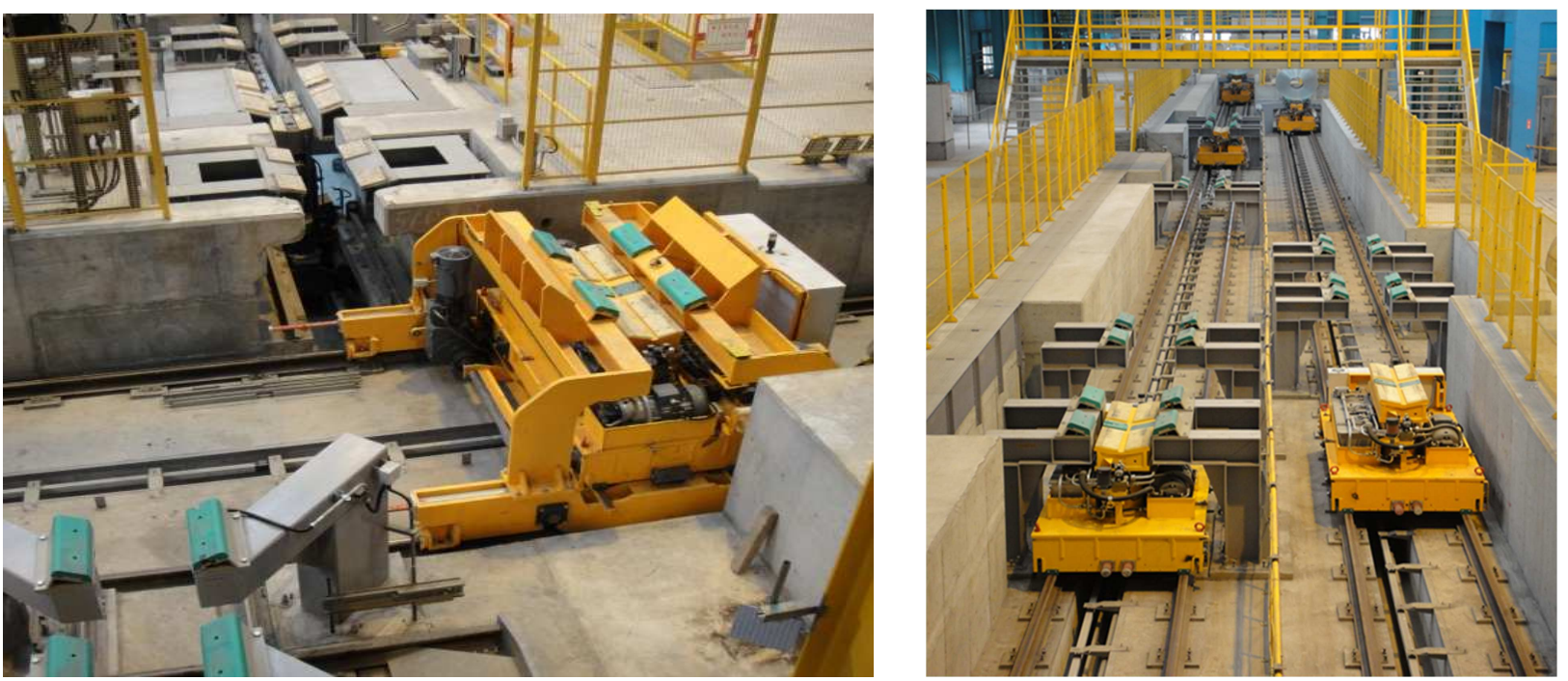

Figure 8: Four way coil cars with side loading skids

Figure 9: Four way coil cars for distribution of the coils in a long bay $>600 \mathrm{M}$ Long. 
Automatic self-loading unloading transfer cars for coil : These cars as seen in figure 8 and 9 above could be self-dependant without needing the service of the EOT crane due to its concept and construction. These cars could operate on rails flush on the floor.

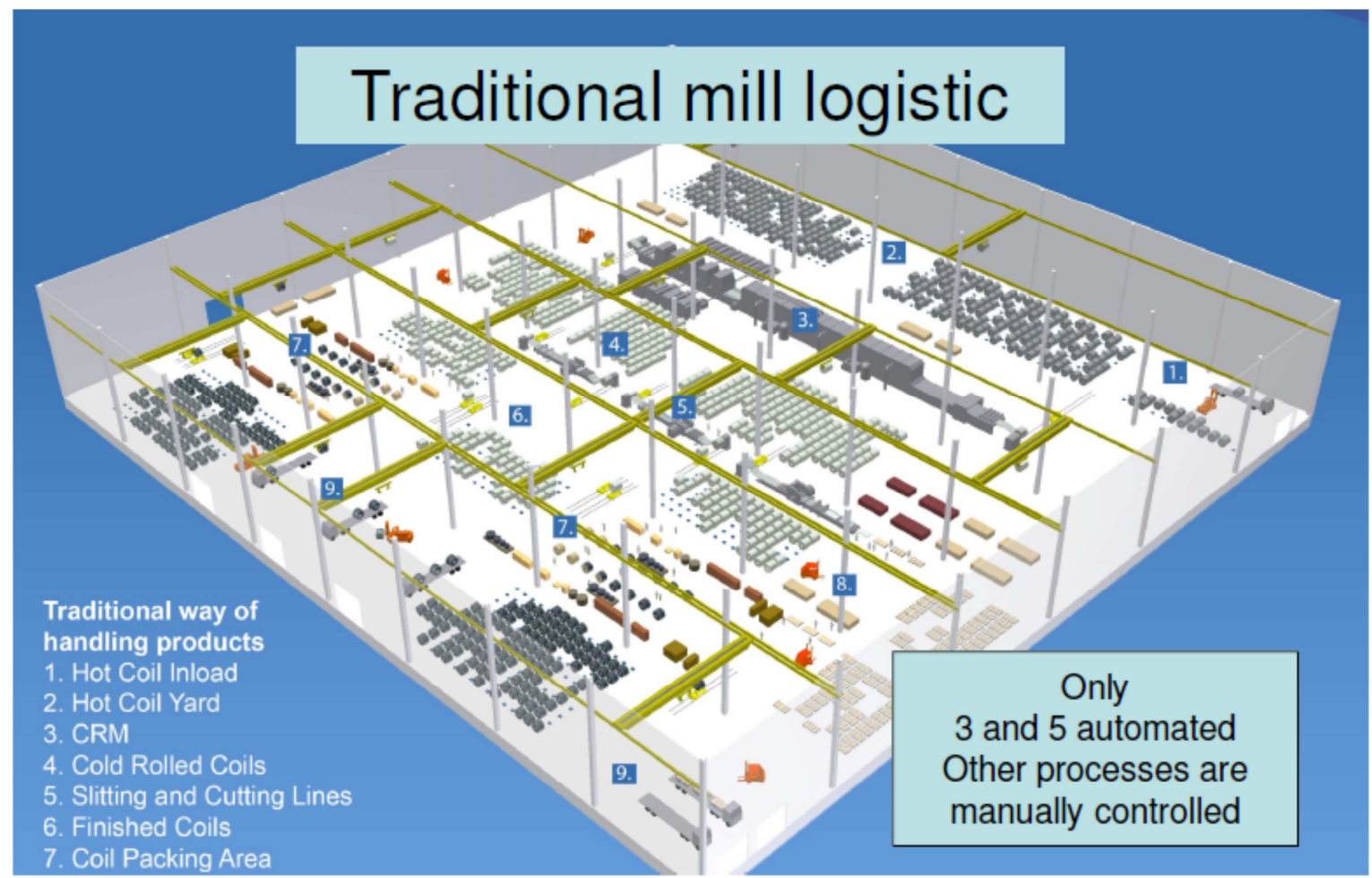

Figure 9: Traditional Mill logistic

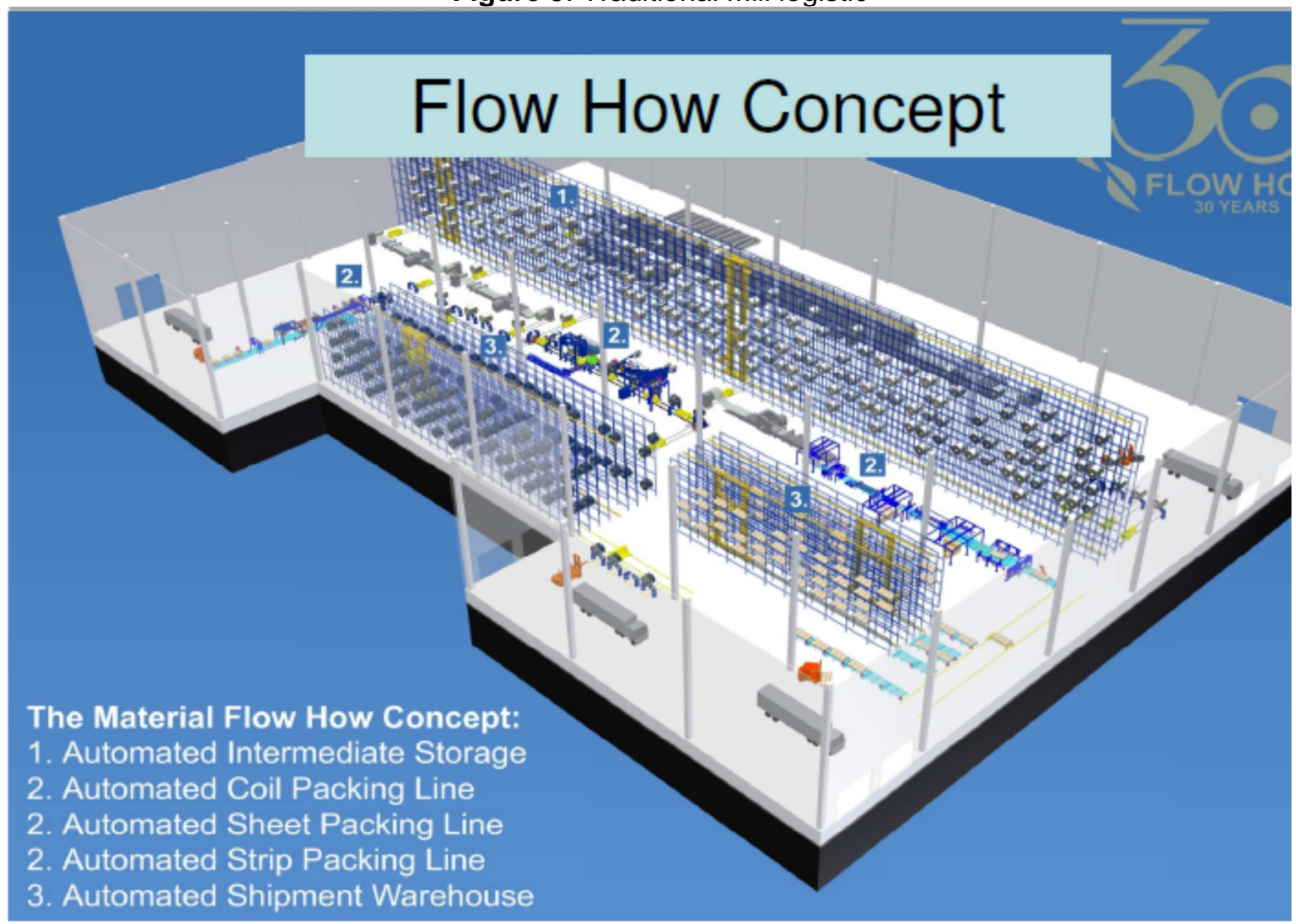

Figure 10: Modern Mill logistic 


\subsection{Yard Management System in JSW CRM2}

The coil handling right from unloading point of the hot rolled coils at PLTCM entry to the Finished goods dispatch are with total automatic tracking and feeding in and out for each process and finishing equipment with integrated planning and production control.
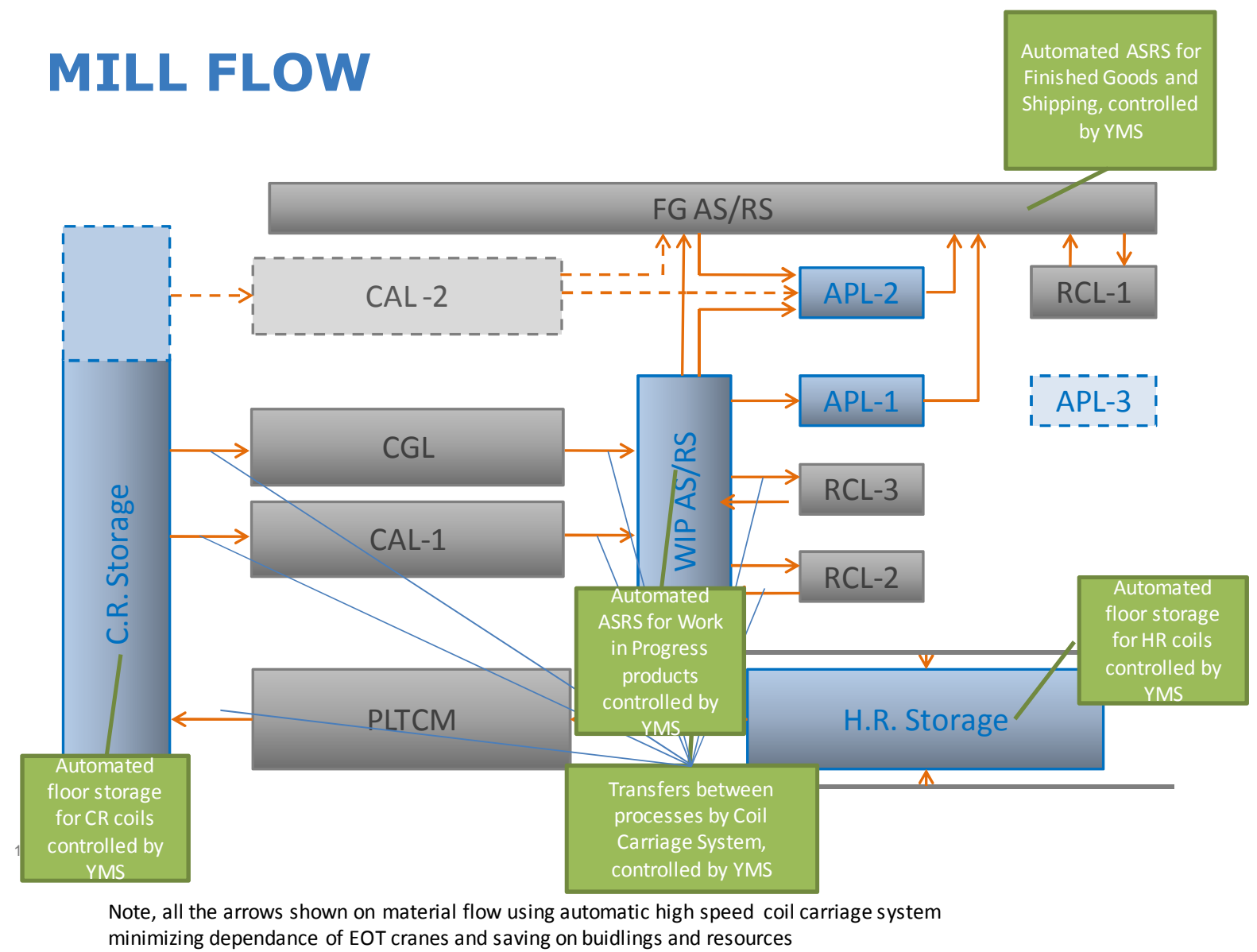

Figure 11: Flow chart of the system

\section{AUTOMATED ASRS WITH RACK SUPPORTED BUILDING AND WMS}

By adopting ASRS there is potential for significant cost savings in steel plants and Galvanizing lines. Integration of production machinery with automatic handling, automated high rise storage, conveyors and an information system could enable the customer to achieve the highest level of efficiency and through put with enhanced profitability.

An automatic Storage and retrieval system (ASRS) with a modern steel warehouse management system can prevent material handling accidents and insuring total quality as the coils are handled in a cradle like a baby with no damage to the side or to the layers. The ASRS could also insure the highest turnover of material received and shipped per hour which is manually unthinkable. 


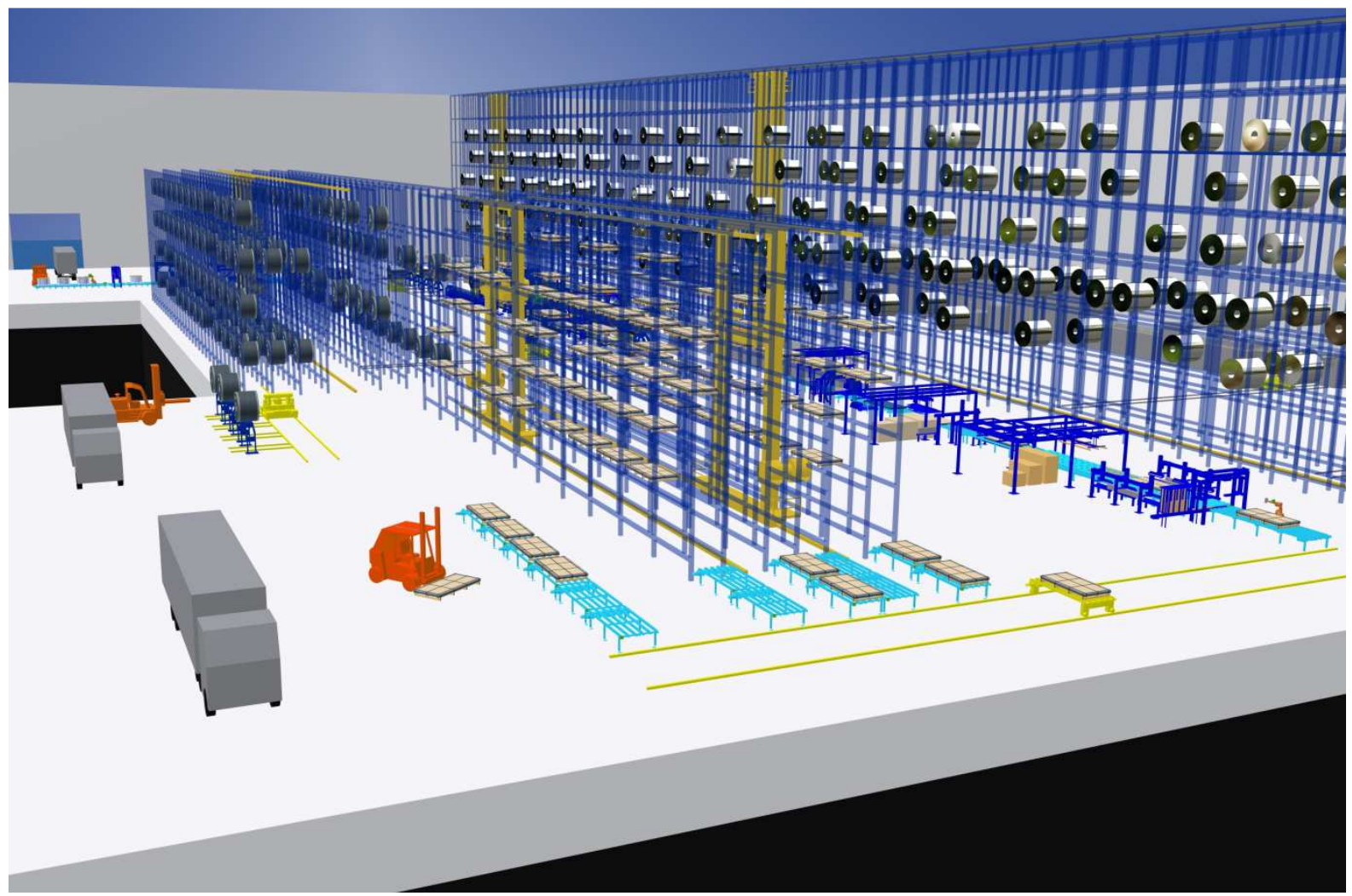

Figure 12: Composite ASRS system for Coils and sheet packs with easy tracking and shipping avenues

An ASRS could be planned for the following applications:

Raw material storage and distribution: Hot rolled coils to be stored and fed to pickling lines and cold rolling mills.

WIP materials storage for process: Cold rolled coils to be stored and fed to Continuous Annealing lines and Galvanizing lines

WIP Materials storage for Finishing: Processed coils to be fed to the recoiling lines , finishing lines and packing lines and retrieved.

Finished goods storage and dispatch: Finished goods from different finishing lines could be received and distributed customer wise for dispatch through wagons and trucks/trailers.

In addition to the fact that the vertical storage could save phenomenally on space the storage itself could have its own rack supported building which further saves on a separate building. The racks support the roof and side cladding suitably increasing the stability and reliability assuring faster construction and economy. 


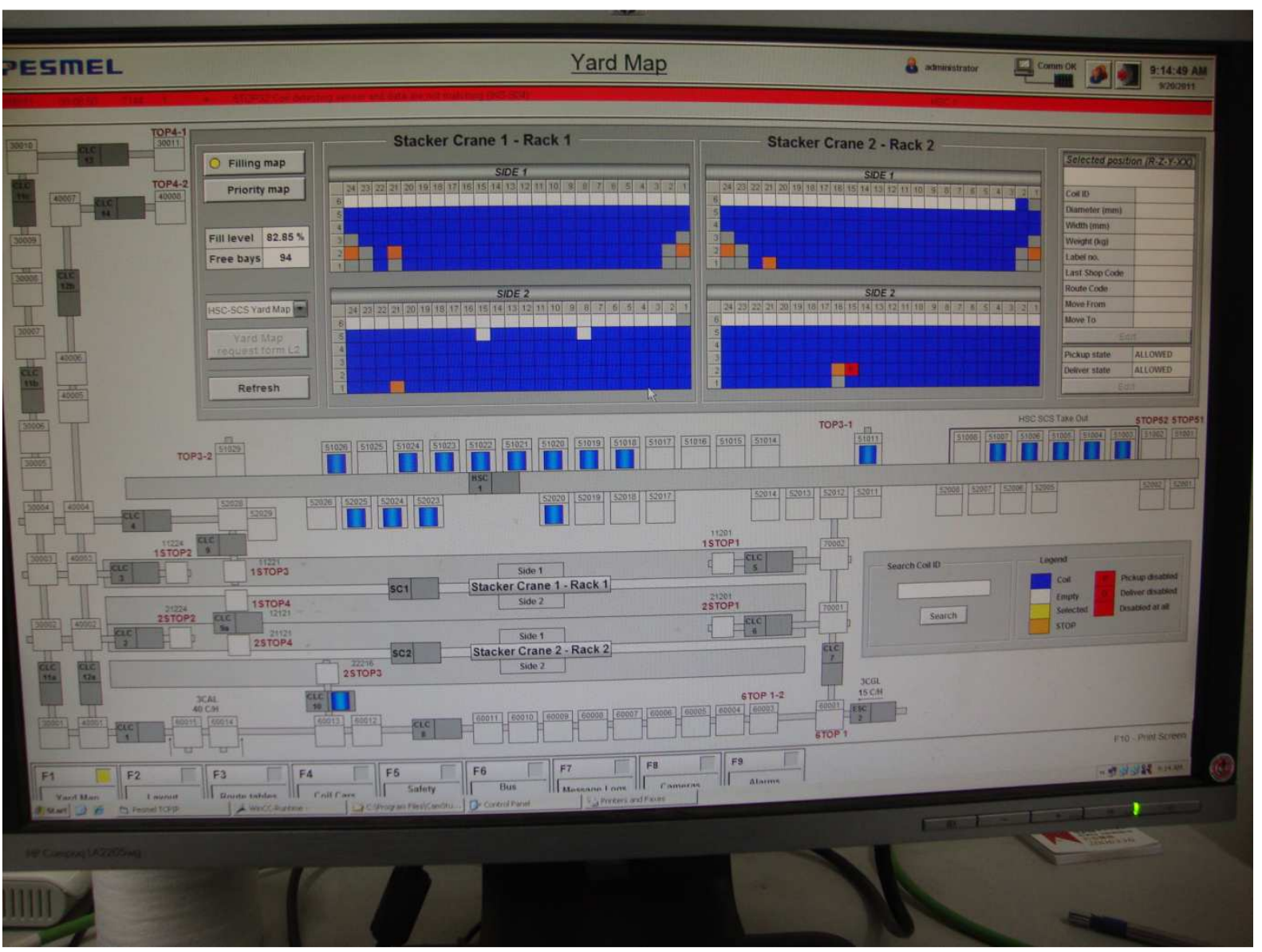

Figure 13: Typical Yard Mapping screen 
Table 1: Comparison of HBW and Floor Storage

\section{Comparison of Coil Storage System With High-Bay Storage vs. Floor Storage}

Parameter

Throughput

(number of coils pe

hour, in and out)

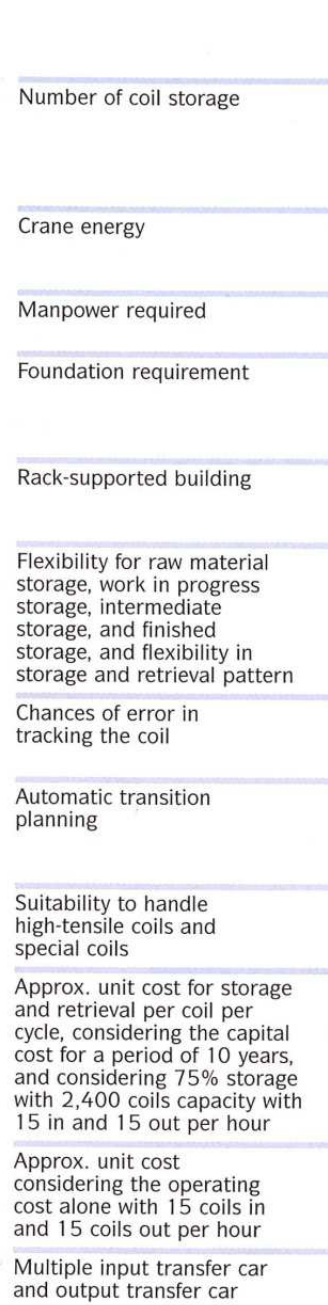

High-bay storage

Could be designed for $\{15+15\}$

to $\{100+100\}$, since stacker cranes

are high-speed cranes and are automatic, with one to two stacker cranes with a cycle time of approx. -2.5 minutes per coil transfer.

Floor-level storage

Remarks

Normally for $\{5+5\}$ to $\{10+10\}$ with three EOT cranes. One coil transfer (pickup, travel and load) typically takes a min. of 7-12 minutes cycle time depending on the distance. The hoist and LT speeds are normally very low compared to stacker cranes.

2,400 full coils of $2 \mathrm{~m} \mathrm{OD} \times 2.2 \mathrm{~m}$ wide could be stored in an area of wide $\times 15 \mathrm{~m}$ high).

2,400 full coils could be stored with allowance for C-hook or coil lifter in an area of $17,550 \mathrm{~m}^{2}$, needing a wide (4 times $600 \mathrm{~m}$ long and $30 \mathrm{~m}$ wide ( 4 times more space).

nigh throughput, high-bay storage is more suitable.

With three EOT cranes, the power tacker cranes consume 1/4 the energy as compared to the EOT cranes.

. stacker crane.

None, except for inspection.

Three to four.

\section{Raft foundation is enough, as the} oad is uniformly distributed.

Pile foundation or heavier foundation may be required for the columns due to concentrated load.

Since 4 times the area is to be structured and roofed, the cost of a The building cost is covere with the rack cost. normal building is increase

Very good due to high throughput capacity. Very flexible and adaptable for multi-tasking.

cow throughput not cross, Also, since the cranes could in storage and retrieval pattern.

For the same height of the building, the area required for vertical storag is approx. 1/4 the area, meaning less cycle time for vertical storage.

There is a savings of approx. $\$ 1$ per coil transfer.

High-bay storage systems are totally automatic.

Foundation is cheaper for vertical storage, considering the lower square footage. Approx. cost savings could $50 \%$.

There could be approx. $20 \%$ cost savings with a rack-supported building.

Multi-tasking is possible for stacker cranes. EOT cranes being slow, it is not possible with minimum cranes.

Negligible High

High

Ideally suitable

Not suitable

Very suitable, as the coil is lifted and transferred in cradles, securing the taitend on the weight of the coil itself.

Not suitable, since with C-hooks there could be springing of the coils once the tail-end is free. $\begin{array}{ll}\begin{array}{l}\text { \$2 per coil. This will be less than } \$ 1 \\ \text { with higher throughput with single }\end{array} & \begin{array}{l}\text { \$3 per coil. This system with three EOT } \\ \text { cranes could not have more throughput }\end{array}\end{array}$ with higher throughput with single cranes could not have more th
than 15 for a 600 -m-long bay.
Reading is more stable in stacker cranes. More error-proof in stacker cranes. Built-in diagnostic system possible.

Stacker cranes are more suitable for process transition planning and feeding energy savings in annealing furnaces.

Stacker crane handles coil more safely with less damage.

Unit component of capital cost in vertical storage system could be $1 / 3$ cheaper than floor storage for greenfield project.
$\$ 0.5$ per coil. This would be directly proportional to the number of coils handled.

\section{Possible}

Limited

$\$ 1.5$ per coil with three EOT cranes.

imited
Operating cost could be three times cheaper in vertical storage system.

\begin{tabular}{|c|c|c|c|}
\hline $\begin{array}{l}\text { Operating convenience and } \\
\text { control }\end{array}$ & Very convenient and dependable & Convenient & $\begin{array}{l}\text { Operating control is better in vertical } \\
\text { storage system. }\end{array}$ \\
\hline Availability & $95-98 \%$ & $90 \%$ due to crane limitation in crossing & $\begin{array}{l}\text { Availability is high in vertical storage } \\
\text { system. }\end{array}$ \\
\hline Maintainability & Easier with maintenance contract & Easier & Maintainability is the same. \\
\hline Reliability & $98-100 \%$ & $90 \%$ & $\begin{array}{l}\text { Reliability of vertical storage is better } \\
\text { since stacker crane is lighter and } \\
\text { trouble-free compared to EOT crane. }\end{array}$ \\
\hline Safety & Very good & Good & $\begin{array}{l}\text { Very good, since there cannot be any } \\
\text { person in the bay for vertical storage. }\end{array}$ \\
\hline $\begin{array}{l}\text { Coil damage chances } \\
\text { due to dropping }\end{array}$ & Less due to cradle handling & More due to $\mathrm{C}$-hook handling & $\begin{array}{l}\text { Coil damage chances are less in } \\
\text { vertical storage system due to cradle } \\
\text { handling. }\end{array}$ \\
\hline $\begin{array}{l}\text { Automatic receipt and } \\
\text { shipping by reading } \\
\text { the documents }\end{array}$ & Possible & Not possible & $\begin{array}{l}\text { Human-less system is possible with } \\
\text { automatic loading transfer cars and } \\
\text { conveyors. }\end{array}$ \\
\hline $\begin{array}{l}\text { System more suitable for } \\
\text { greenfield or brownfield? }\end{array}$ & Greenfield & Brownfield & $\begin{array}{l}\text { Vertical storage system is more suitable } \\
\text { from greenfield stage for new projects } \\
\text { with good planning. }\end{array}$ \\
\hline $\begin{array}{l}\text { Overall cost advantage } \\
\text { and return on investment* }\end{array}$ & $\begin{array}{l}\text { An estimated IRR of } 35 \% \text { and } \mathrm{ROI} \text { in } \\
3 \text { years with many operating } \\
\text { conveniences. IRR is calculated based } \\
\text { on increase in productivity and unit cost. }\end{array}$ & $\begin{array}{l}\text { An estimated IRR of } 20 \% \text { and } 5 \text {-year } \\
\text { return on investment, with many } \\
\text { operating inconveniences, especially } \\
\text { with multi-tasking. }\end{array}$ & $\begin{array}{l}\text { Both IRR and ROI are better in vertical } \\
\text { storage system. }\end{array}$ \\
\hline
\end{tabular}

* Depends on the specific production planning svstem followed in each companv. 


\subsection{Rack Supported Building}

A Rack Supported warehouse is where the racking meant for holding the material is also used to support the walls and roof of the warehouse. It makes sense to utilize the racking (with storage of steel coils or plates or sheet packs or long products) which has the high modulus of rigidity and bulk strength for supporting the roof and side claddings with appropriate purlins. The racking will take up besides bay load the crane loads and seismic forces as well external loads like for example forces from wind snow, wall and roof cladding, Figure 14. Considering that the cost of land, materials and labour continue to rise, the Rack Supported Building concept becomes a more economical warehousing solution to high bay storage of above 25 meters with Automatic handling Warehouse Management system (WMS). These warehouses consist of the racking system that provides the basic structural support for the building's roof and walls. Maximum density storage solution possible for every type of pallet rack is reducing the construction costs, lead times and building footprint. Rack supported building concept is obviously the optimum solution to store at a large heights making the most of the available surface.
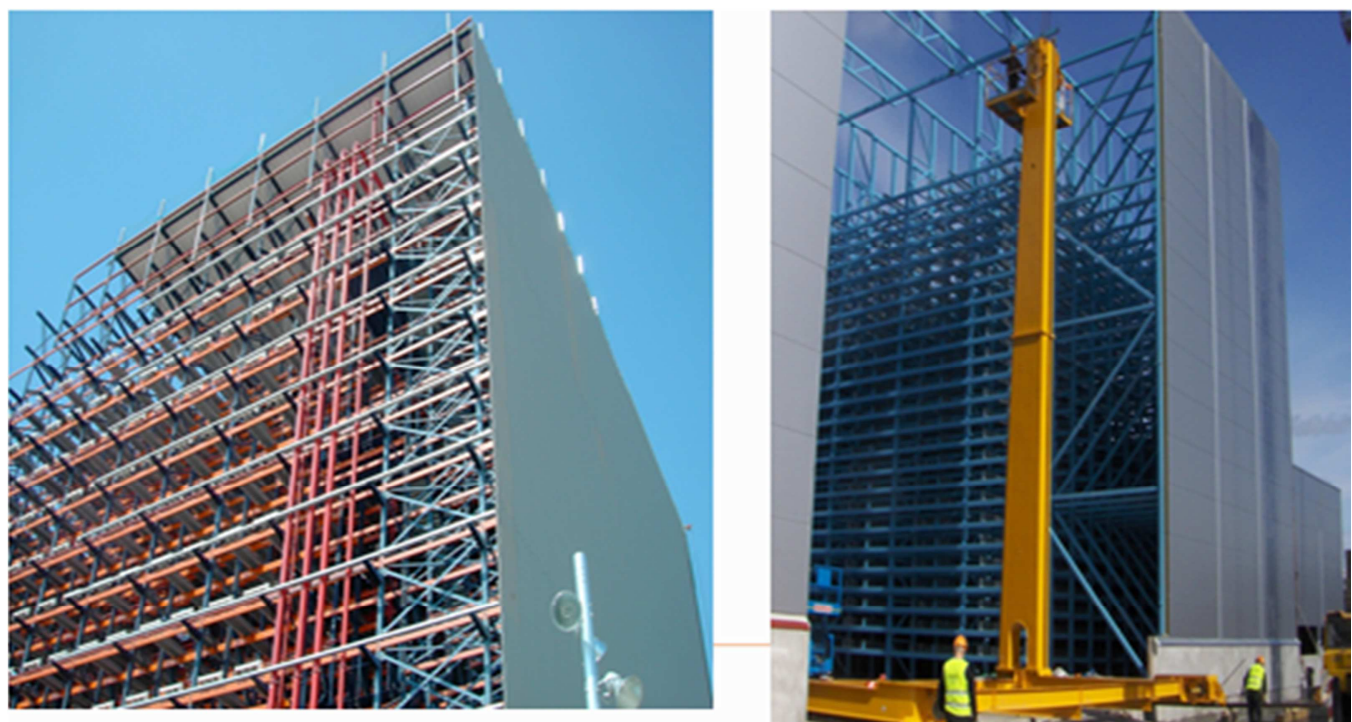

Figure 14: Racks supporting the roof and side cladding

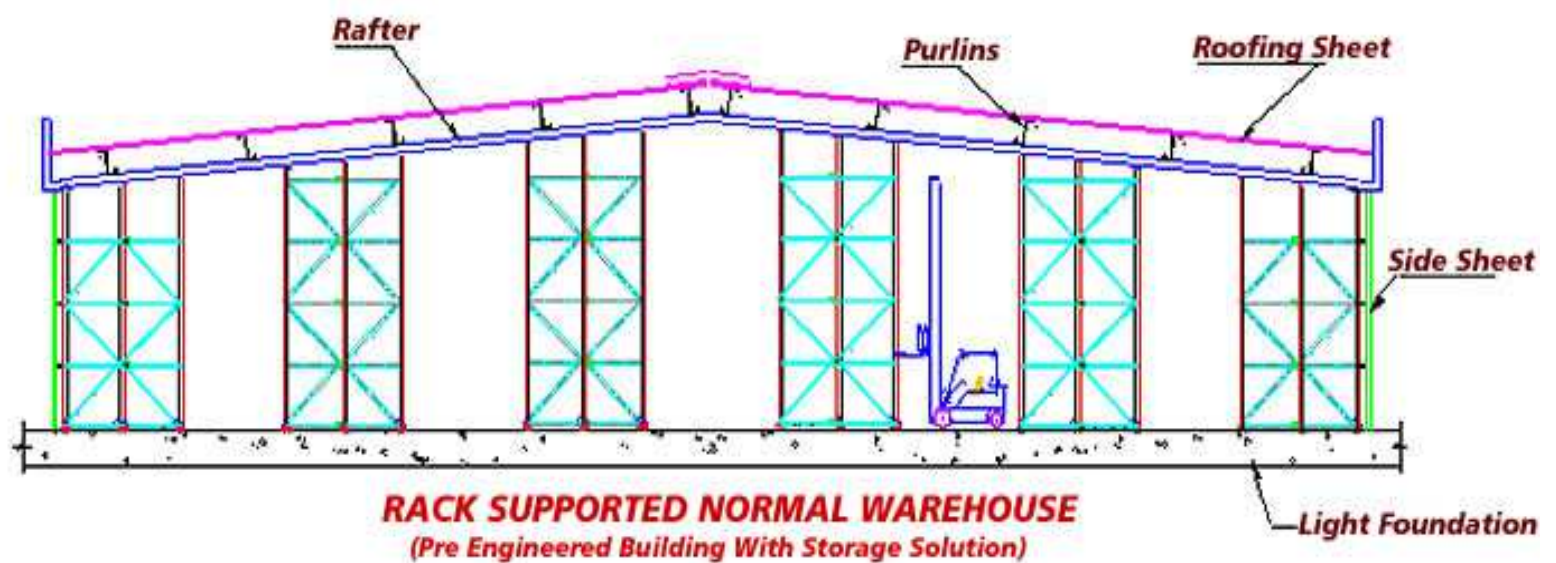

Figure 15: RSW concept 


\subsection{Free Standing Rack Construction}

Free standing rack construction means that the system has to take up bay load (Figure 11), crane loads and seismic forces, but no external loads like wind, snow, wall and roof cladding. This has the benefit that the racking construction can be built approx. 10\% lighter but needs another separate building which could cost approx. $60 \%$ more with many operating and installation inconveniences.

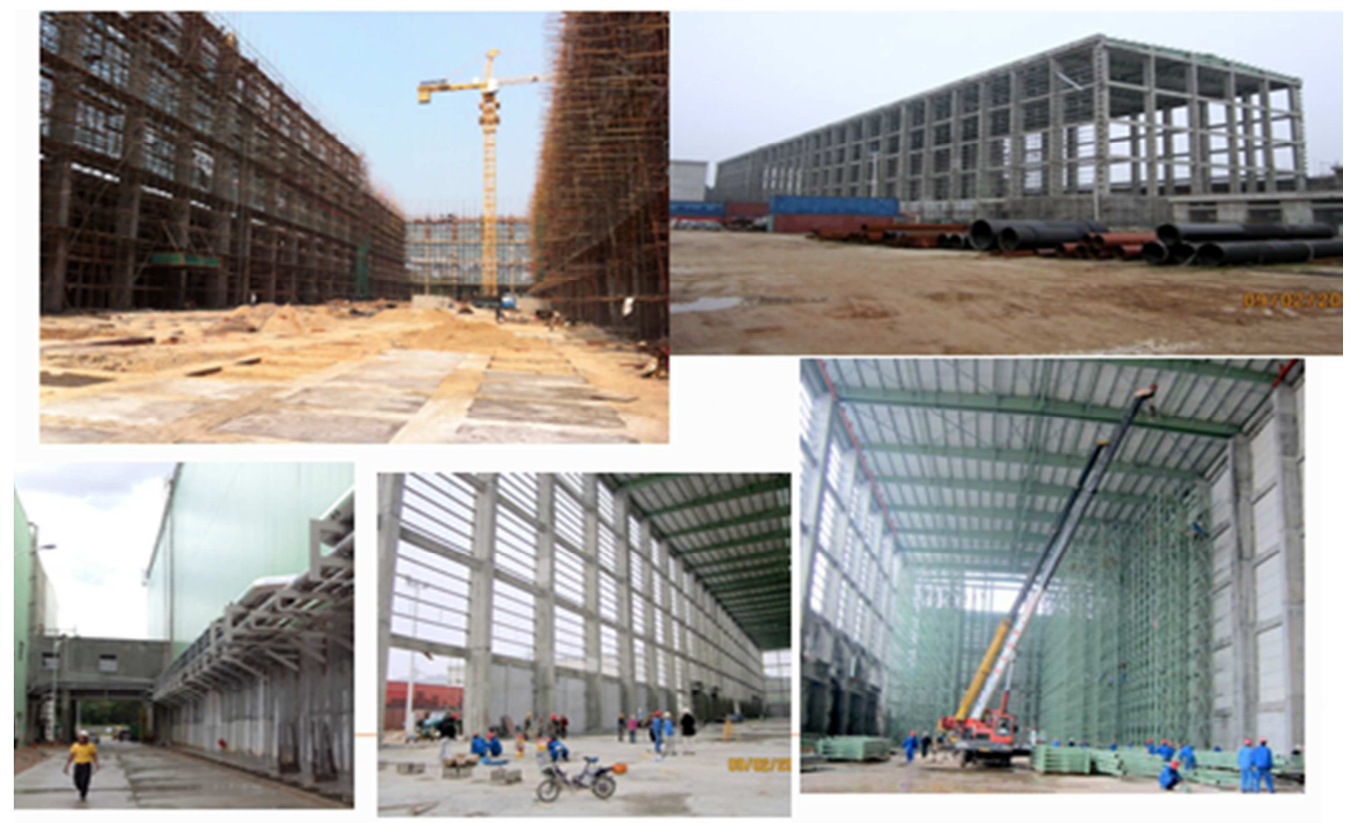

Figure 16: Typical free standing rack constructions

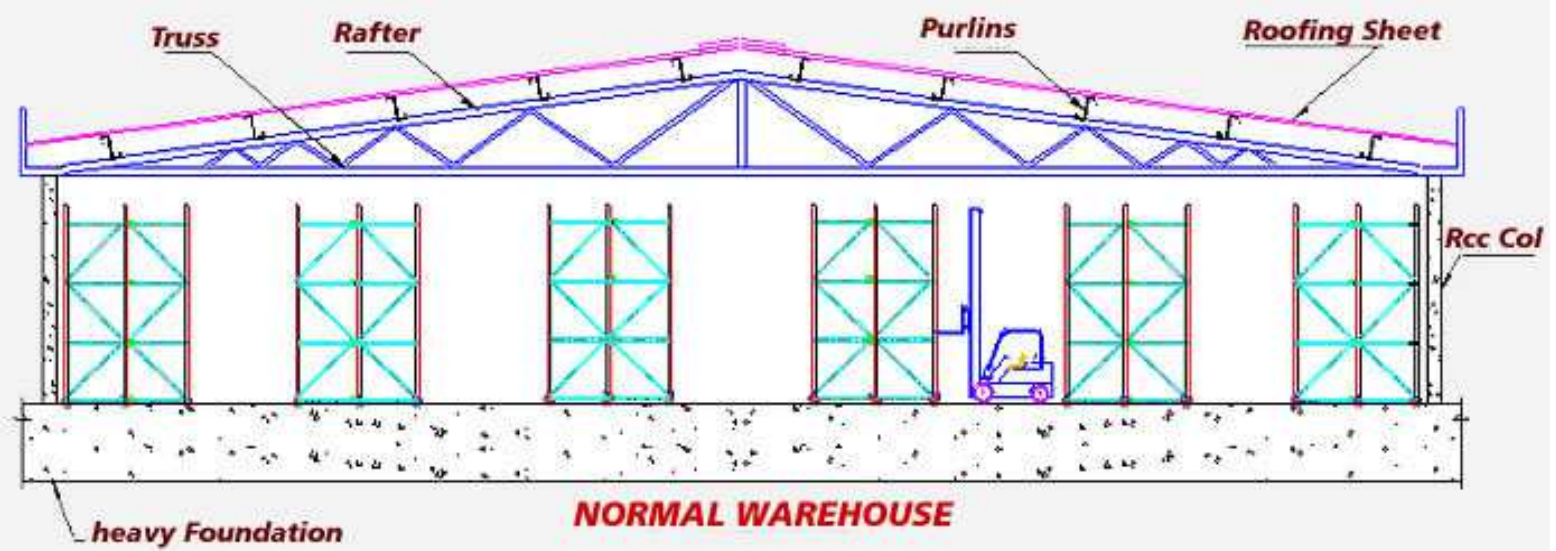

Figure 17: Old type free standing warehouses

The specialty of this construction is that it does not require conventional structural columns to support the walls and roof. They are fixed directly on to the racking structure to complete the building. There are no interference with building columns and also huge savings realized in construction time and cost. Rack concept construction requires extremely accurate engineering tolerances. 
5.3. Construction Sequence and Configuration Features comparison

Normal warehouse

Heavy foundation work

slab and

Large redundant Columns

Roofing and side cladding,

required supported on columns and trusses
Rack supported Warehouse (RSW)

Construction could start with Raft and unit foundation work per ton stored

Uniform Racks

Supported on Racks. No truss

\begin{tabular}{|ll|}
\hline Gable end Wind girders & Not required \\
\hline $\begin{array}{l}\text { After this flooring and then } \\
\text { Racking work starts }\end{array}$ & RSW is complete in the previous step \\
\hline Less height for storage & More height for storage \\
\hline Static building & Dynamic building with WMS \\
\hline Less utilization space & Best Utilization of space and volume \\
\hline Low storage capacity per unit area & High storage capacity per unit area \\
\hline Approximate 7 Sq M per coil storage & $\begin{array}{l}\text { In 7 Sq M utilizing the height } \\
\text { approx. 14 coils could be stored. }\end{array}$ \\
\hline $\begin{array}{l}\text { Low Efficiency and throughput } \\
\text { throughput }\end{array}$ & High operating efficiency and \\
\hline $\begin{array}{l}\text { Costly considering low efficiency } \\
\text { cycle and high resource requirement } \\
\text { stringent monitoring requirement }\end{array}$ & $\begin{array}{l}\text { Most cost effective with lowest life } \\
\text { cost }\end{array}$ \\
\hline $\begin{array}{l}\text { Semiautomatic Yard Management } \\
\text { Management System (YMS) }\end{array}$ & $\begin{array}{l}\text { Totally automatic Warehouse } \\
\text { System (WMS) }\end{array}$ \\
\hline Less safe due to Human interface & $\begin{array}{l}\text { Total Safety with no people } \\
\text { physical interface }\end{array}$ \\
\hline
\end{tabular}

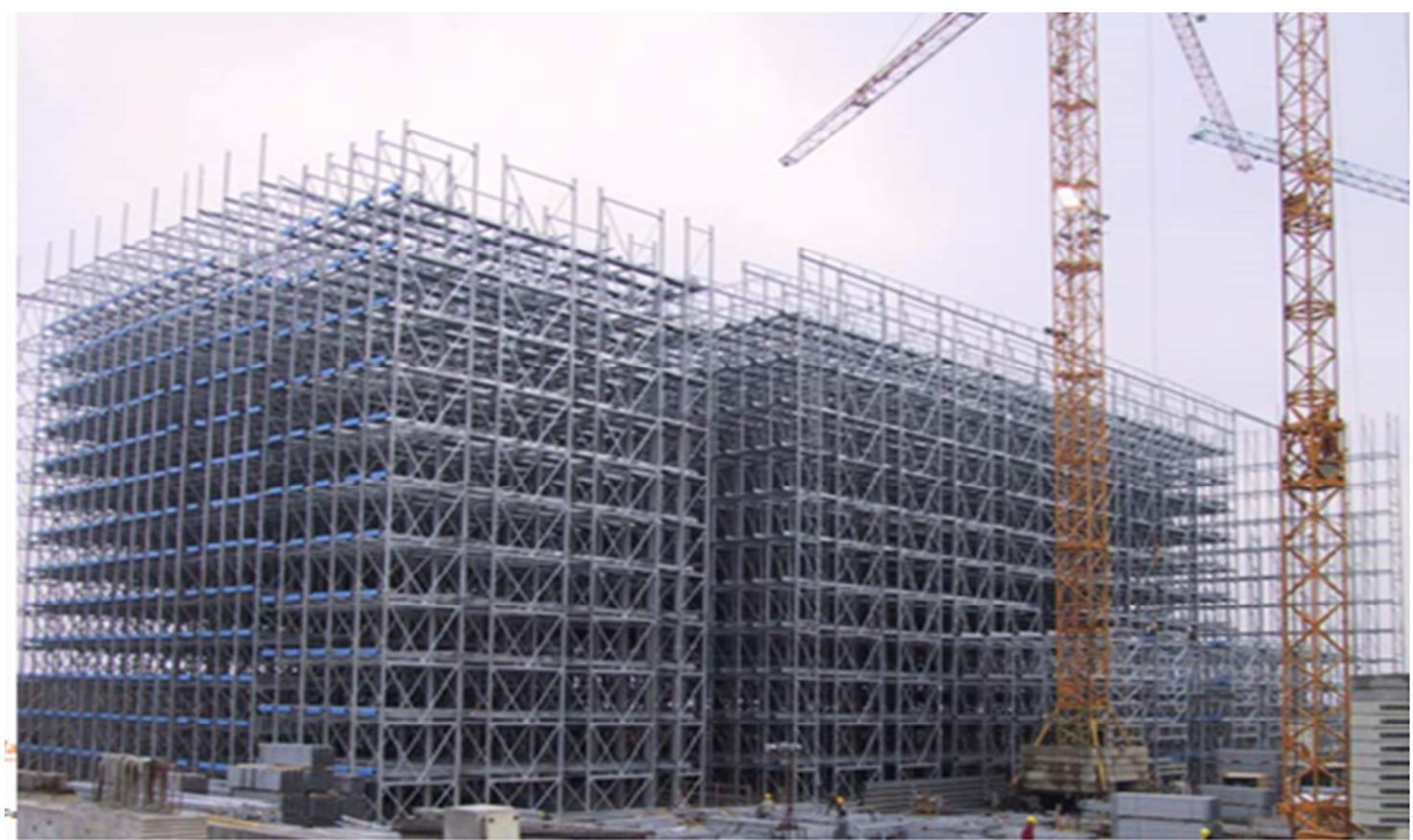

Figure 18: Integrated Racks and cladding simple example 


\subsection{Rack Supported Warehouse (RSW) Advantages}

- Turnkey solution. Please refer to table 2.

- Integrated easily with an AS/RS system

- Eliminates building columns since rack supports the structure

- Can be built at heights $>100 \mathrm{ft}(30 \mathrm{M})$

- Inclement weather and Seismic conditions have less impact on RSW

- Utilizes height instead of large land mass

- Tax advantages may be available for less energy consumption design

- Economical due to savings in cost of construction

- Lighter rafter and purlin sections due to close spacing of the racks.

- Optimal spacing with high efficient Material Handling equipment like Vertical Stacker cranes

- No lighting required and may be required for the aisles for maintenance inspection

- All merits of Pre engineered Buildings

- The rack and building frame work are the same structures

- No building columns interfere with the storage or material handling

- Installation takes very little time compared to conventional building and addition of Racks, cranes and other accessories

- Engineering and Architectural time reduced

\subsection{Rack Supported Warehouse at JSW CRM 2}

Based on the configuration and simulation study the rack supported vertical storage system ASRS was configured and justified matching with the storage requirement and throughout per hour. The Storage system is configured in two phases with $50 \%$ $+50 \%$ The area required for storing typically for 2000 coils is approx. 2700 Square meters $(300 \times 9)$ by utilizing the height up to 33 meters.

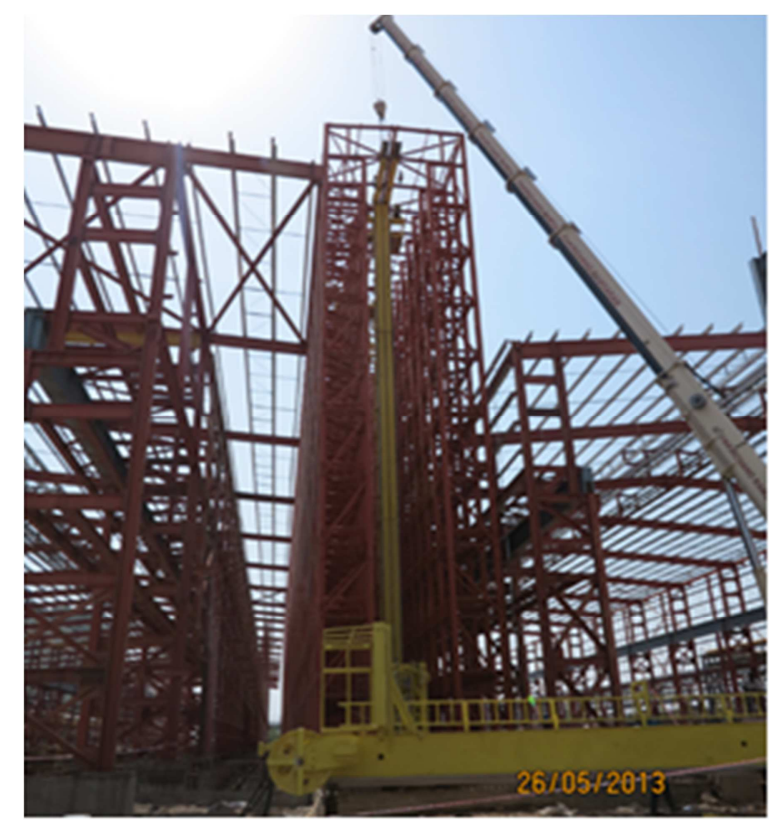

Figure 19: Rack supported warehouse in JSW 


\section{CONCLUSION}

- Savings in constructions by avoiding unnecessary buildings

- Saving on Cranes (MHE) and resources

- High storage density and through put per hour

- Reduction of construction time lines as erection of racks cladding and material handling $(\mathrm{MH})$ equipment can be undertaken simultaneously

- Single turnkey for storage, building and material handling and loading points including ventilation and lighting

- Phenomenal Energy saving assuring safety for people and material with absolute error free tracking

- TOTAL SAFETY due to (WMS) assisted people free operations system.

\section{BIBLIOGRAFIA}

1 Pesmel Archives and JSW archives

2 Rack supported building, presentation by Jouni Räisanen 2012

3 ASRS for Steel Plants and Warehouses, Jagannathan Rajagopalan and Sanna Rintatalo, June 2010 AIST Magazine.

4 Configuration and Simulation study, Teemu Kolkka, Jagannathan Rajagopalan and Juha Suksi, June 2013, AIST Magazine

5 http://www.pesmel.com

6 http://www.jsw.in/. 